26(2), 349-360

\title{
Daily Peak Load Forecasting for Electricity Demand by Time series Models
}

\author{
Jeong-Soon Lee ${ }^{a} \cdot$ H. G. Sohn ${ }^{a} \cdot$ S. Kim ${ }^{a, 1}$ \\ ${ }^{a}$ Department of Applied Statistics, Chung-Ang University
}

(Received February 26, 2013; Revised April 5, 2013; Accepted April 5, 2013)

\begin{abstract}
Forecasting the daily peak load for electricity demand is an important issue for future power plants and power management. We first introduce several time series models to predict the peak load for electricity demand and then compare the performance of models under the RMSE(root mean squared error) and MAPE(mean absolute percentage error) criteria.
\end{abstract}

Keywords: Seasonal AR-GARCH, Holt-Winters, Reg-ARIMA, electricity demand, peak load.

\section{1. 서론}

통계적 수요예측은 다양한 분야에서 자료를 분석하고 예측하는데 널리 쓰이는 기법이다. 시계열 분석은 시간의 흐름에 따라 변하는 경제 현상이나 자연 현상을 일정한 시간간격으로 관찰하여 얻어진 자료를 이 용하여 수요를 예측하는 기법으로 특정 시점의 시계열 관측값은 그 이전 자료들에 의존하게 된다. 시계 열 분석 방법은 다양한 경제, 경영활동 분야에서 연구되고 있으며, 최근에 전력 수요를 비롯한 공학 분 야의 자료 예측에도 적용되고 있다. 정확한 전력수요 예측은 고객의 수요를 예측하고 전력을 상품으로 거래하는데 있어서 특히 중요하다. 현재 모든 이의 생활에 전력이 이용됨에 따라 잘못된 전력수요의 예 측은 우리의 생활에 직접적인 피해를 준다. 일례로 2011년 9월 순환정전 사태가 발생으로 인하여 많은 사업체와 사용자들이 큰 피해를 입었다. 최대사용량의 $30 \%$ 가 예비전력으로 준비되어야 하지만, 공급능 력이 $0 \%$ 까지 떨어짐에 따라 정전 사태 발생원인으로 발생하였다. 순환 정전을 넘어서 블랙아웃 사태로 치달을 만큼 잘못된 예측이 가져오는 피해는 막심하다. 이러한 문제를 예방하기 위해 전력 수요의 효율 적인 예측에 대한 다양한 방법들이 연구되고 있다. Ramanathan 등 (1997)는 지수평활법을 사용하여 온도와 기간을 고려한 수정 모형을 제안하였으며, Taylor와 Buizza (2003)은 날씨 변수를 이용하여 전 력수요를 예측하였고, Taylor (2003)은 이중계절 지수평활법을 이용하여 전력수요를 예측하였다. 또한, Taylor (2010)은 삼중계절 방법이 이중계절 방법보다 전력수요를 예측하는데 성능이 우수함을 보였다. Sohn과 Lim (2005)은 AR-GARCH 모형을 제안하였으며, Weron (2006)은 ARIMA 모형을 이용한 예 측방법을 통하여 우수성을 보였다. Amjady (2001)은 시간별 자료에 기온을 고려하여 수정된 ARIMA 모형을 사용하였고, McSharry 등 (2005)은 기상상태를 고려한 회귀모형을 사용하였다.

This research was supported by the Chung-Ang University Research Scholarship Grants in 2011.

${ }^{1}$ Corresponding author: Professor, Department of Applied Statistics, Chung-Ang University, 221 HeukseokDong, Dongjak-Gu, Seoul 156-756, Korea. E-mail: sahm@cau.ac.kr 
가장 흔하게 계절주기를 모델링하는데 쓰이는 접근방법으로는 Holt-Winters 지수평활법과 ARIMA 모 형이 있다. Holt-Winters 접근은 몇 가지 약점이 있는데, 그것은 시작값이 필요하고 각 일자별 특정 시 간에 유사성을 찾지 못한다는 것이다. 또한 다른 날들의 패턴을 조정하는 것이 가능하지 않다. Taylor (2003)은 다른 주기에 포함된 주기를 이용하는 이중 계절 지수평활법을 개발하였다. 테일러의 방법은 예측값의 상당한 개선을 보이지만 시간당 자료를 이용하여 분석할 때 일주일의 모든 날들이 같은 일별주 기를 가진다고 가정한다. 기온을 고려하기 위하여 대표적으로 사용되는 모형은 REG-ARIMA 모형으 로 시계열적 패턴과 온도를 동시에 고려할 수 있는 모형 구축이 가능하다. Amjady (2001)는 이러한 외 부적인 영향을 ARIMA 모형에 고려하였다.

전력수요 예측에서 계절성은 중요한 특징 중의 하나이므로 본 연구는 계절형 ARIMA 모형과 HoltWinters 지수평활(Exponential smoothing) 모형과 Taylor (2003)에 의해 수정된 Holt-Winters 지수평 활법, 분산의 이분산성을 설명할 수 있는 AR-GARCH(Generalized Autoregressive Conditional heteroskedasticity), 평균기온을 고려한 REG-ARIMA 모형을 이용하여 전력수요의 예측 성능을 비교하고 결합 예측 방법을 이용하여 단순 예측과 비교하고자 한다.

\section{2. 시계열 모형의 소개}

\section{1. 계절형 ARIMA(SARIMA) 모형}

단변량 시계열 모형 중 수요예측에 사용하는 분석 방법 중에서 가장 널리 이용되는 방법의 하나는 Box와 Jenkins (1994)의 계절형 자기회귀누적이동평균(Autoregressive Integrated Moving Average; ARIMA) 모형이다. ARIMA 모형은 다른 설명변수의 도입이 없어도 교란항과 과거치 만으로 시계열에 적합한 모형을 설정할 수 있도록 하는 가장 기본적인 방법이으로, 단기예측과 계절형 변동을 포함하는 시계열의 분석에 효과적이다.

Box의 이중 계절형 자기회귀누적의 기본 형태를 보면 아래의 모형과 같다.

$$
\phi_{p}(B) \Phi_{P_{1}}\left(B^{s_{1}}\right) \Pi_{P_{2}}\left(B^{s_{2}}\right)(1-B)^{d}\left(1-B^{s_{1}}\right)^{D_{1}}\left(1-B^{s_{2}}\right)^{D_{2}} Z_{t}=\theta_{q}(B) \Theta_{Q_{1}}\left(B^{s_{1}}\right) \Psi_{Q_{2}}\left(B^{s_{2}}\right) \epsilon_{t},
$$

여기서 $c$ 는 상수항을 말하고, $B$ 는 $B^{k} Y_{t}=Y_{t-k}$ 에 연산을 맡는 후진연산자이고, $\phi_{p}(B)$ 와 $\theta_{q}(B)$ 는 $p$ 차 $\mathrm{AR}$ 과 $q$ 차 $\mathrm{MA}$ 를 의미하며, $\Phi_{P_{1}}\left(B^{s_{1}}\right), \Pi_{P_{2}}\left(B^{s_{2}}\right), \Theta_{Q_{1}}\left(B^{s_{1}}\right), \Psi_{Q_{2}}\left(B^{s_{2}}\right)$ 는 $s_{1}, s_{2}$ 에 따르는 $P_{1}, P_{2}$, $Q_{1}, Q_{2}$ 차 계절성 $\mathrm{AR}$ 과 계절성 $\mathrm{MA}$ 를 의미한다. $d, D_{1}, D_{2}$ 는 차분의 차수를 말하며 $\epsilon_{t}$ 는 평균 0 과 고 정된 분산을 따르는 백색잡음과정이다. 다항식 $\phi_{p}(B)=0, \theta_{q}(B)=0, \Theta_{Q_{1}}\left(B^{s_{1}}\right)=0, \Psi_{Q_{2}}\left(B^{s_{2}}\right)=0$, $\phi_{P_{1}}\left(B^{s_{1}}\right)=0, \Phi_{P_{2}}\left(B^{s_{2}}\right)=0$ 의 단위근은 단위원 밖에 위치한다.

\subsection{Holt-Winters 지수평활모형}

Winters (1960)에 의해 제안된 Winters의 가법적 계절지수평활법(additive seasonal exponential smoothing)은 시계열이 추세성분과 계절성분 및 불규칙성분들의 합으로 구성되어 있다고 보고 각 성분들을 이용하여 예측값을 구하는 방법이다. 가법적 계절지수평활법은 시계열의 평균수준이 시간의 흐름에 따라 변화하지만 분산은 시간의 흐름에 관계없이 일정한 경우 사용되는 방법이다. 홀트-윈터스 가법적 계절지수평활법은 수평성, 추세성, 계절성을 평활시키는 세 개의 방정식과 예측식으로 구성된다. 현재 시점이 $t$ 인 경우 $h$ 시점 후의 예측값은 식 $(2.2)$ 와 같다.

$$
F_{t+h}=L_{t}+T_{t} \times h+S_{t+h-s} .
$$


식 (2.2)에서 $L_{t}$ 은 수평성분, $T_{t}$ 은 추세성분, $S_{t}$ 은 계절성분을 나타내고 각각의 요소는 식 (2.3)과 같이 정의된다.

$$
\begin{aligned}
L_{t} & =\alpha\left(Z_{t}-S_{t-s}\right)+(1-\alpha)\left(L_{t-1}+T_{t-1}\right), \\
T_{t} & =\beta\left(L_{t}-L_{t-1}\right)+(1-\beta) T_{t-1}, \\
S_{t} & =\gamma\left(Z_{t}-L_{t}\right)+(1-\gamma) S_{t-s} .
\end{aligned}
$$

위 식에서 $Z_{t}$ 은 원시계열 자료이고, $\alpha, \beta, \gamma$ 는 평활상수를 나타낸다. 모든 평활상수 값은 0 과 1 사이의 값을 가진다.

이중 계절성을 적용시한 계절형 Holt-Winters 지수평활법은 식 (2.4)와 같이 적용된다. 여기서 $Z_{t}$ 는 고 려할 $t$ 시점의 전력수요량으로 계절주기를 $s_{1}$ 과 $s_{2}$ 라 하면 $L_{t}$ 는 $t$ 시점의 평활수준을 나타내고 $T_{t}$ 는 $t$ 시 점의 평활가법추세를 의미하며, $S_{t}$ 와 $D_{t}$ 는 $t$ 시점의 계절주기 $s_{1}$ 과 $s_{2}$ 의 계절지표를 의미한다.

$$
\begin{aligned}
F_{t+h} & =L_{t}+T_{t} \times h+S_{t+h-s_{1}}+D_{t+h-s_{2}}, \\
L_{t} & =\alpha\left(Z_{t}-S_{t-s_{1}}-D_{t-s_{2}}\right)+(1-\alpha)\left(L_{t-1}+T_{t-1}\right), \\
T_{t} & =\beta\left(L_{t}-L_{t-1}\right)+(1-\beta) T_{t-1}, \\
S_{t} & =\gamma\left(Z_{t}-L_{t}-D_{t-s_{2}}\right)+(1-\gamma) S_{t-s_{1}}, \\
D_{t} & =\delta\left(Z_{t}-L_{t}-S_{t-s_{1}}\right)+(1-\delta) D_{t-s_{2}} .
\end{aligned}
$$

식 (2.4)의 초기값은 식 (2.5)의 계산을 통하여 나타난다.

$$
\begin{aligned}
L_{s_{1}} & =\frac{1}{s_{1}} \sum_{t=1}^{s_{1}} Z_{t}, \quad L_{s_{2}}=\frac{1}{s_{2}} \sum_{t=1}^{s_{2}} Z_{t} \\
T_{s_{1}} & =\frac{1}{s_{1}^{2}}\left(\sum_{t=s_{1}+1}^{2 s_{1}} Z_{t}-\sum_{t=1}^{s_{1}} Z_{t}\right), \quad T_{s_{2}}=\frac{1}{s_{2}^{2}}\left(\sum_{t=s_{2}+1}^{2 s_{2}} Z_{t}-\sum_{t=1}^{s_{2}} Z_{t}\right) \\
S_{1} & =Z_{1}-L_{s_{1}}, \ldots, S_{s_{1}}=Z_{s_{1}}-L_{s_{1}} \\
D_{1} & =Z_{1}-L_{s_{2}}, \ldots, D_{s_{2}}=Z_{s_{2}}-L_{s_{2}} .
\end{aligned}
$$

평활상수 $\alpha, \beta, \gamma, \delta$ 의 추정은 이 $m$ 개의 모형추정자료를 통하여 추정가능하다. 모형추정단계 중 1 차 시 점 예측에서 $\mathrm{SSE}$ (Sum of Squared Error)를 최소화하는 과정을 통하여 계산되며, SSE는 식 (2.6)에 의 하여 계산된다.

$$
\mathrm{SSE}=\sum_{t=2}^{m}\left(Y_{t}-Z_{t}\right)^{2} .
$$

\section{3. 수정 Holt-Winters 모형}

수정 이중계절 Holt-winters 지수평활법은 Taylor (2003)에 의하여 제안되었다. 수정 Holt-Winters 지 수평활법은 식 (2.4)에서 $F_{t+h}$ 를 식 (2.7)과 같이 변형하여 정의한다.

$$
F_{t+h}=L_{t}+T_{t} \times h+S_{t+h-s_{1}}+D_{t+h-s_{2}}+\phi^{h}\left[Z_{t}-L_{t-1}-T_{t-1}-S_{t-s_{1}}-D_{t-s_{2}}\right]
$$

$\phi$ 는 1 차 상관계수에 조정을 나타내는 값으로 평활 모수 $\alpha, \beta, \gamma, \delta, \phi$ 는 1 차 예측단계에서 $\operatorname{SSE}(\operatorname{Sum}$ of Squared Error)를 최소화하는 과정을 통하여 계산된다. 


\subsection{Reg-ARIMA 모형}

기존 ARIMA 모형에서 평균기온을 고려하기 위하여, Reg-ARIMA 모형을 고려한다. Reg-ARIMA 모 형은 Regression(회귀)와 ARIMA의 합성어로서 회귀분석 방법을 통하여 사전조정을 실시하고 Seasonal ARIMA 모형을 예측한다. 사전조정요인과 관련된 $r$ 개의 회귀변수 $x_{j t}$ 와 $t$ 시점의 자료 $y_{t}$ 를 고 려한 $\operatorname{ARIMA}(p, d, q)\left(P_{1}, D_{1}, Q_{1}\right)_{s_{1}}\left(P_{2}, D_{2}, Q_{2}\right)_{s_{2}}$ 는 식 $(2.8)$ 과 같이 표현한다.

$$
\begin{aligned}
& \phi_{p}(B) \Phi_{P_{1}}\left(B^{s_{1}}\right) \Pi_{P_{2}}\left(B^{s_{2}}\right)(1-B)^{d}\left(1-B^{s_{1}}\right)^{D_{1}}\left(1-B^{s_{2}}\right)^{D_{2}}\left(y_{t}-\sum_{j=1}^{r} \beta_{j} x_{j t}\right) \\
& =\theta_{q}(B) \Theta_{Q_{1}}\left(B^{s_{1}}\right) \Psi_{Q_{2}}\left(B^{s_{2}}\right) \epsilon_{t} .
\end{aligned}
$$

\section{5. 계절형 AR-GARCH 모형}

전통적인 시계열모형에서는 분산이 시간에 따라 변하지 않는다는 등분산을 가정하고 있으나, 시계열 예 측 및 모델링을 하는 데에 있어 분산이 과거의 자료에 의존하는 특성인 이분산성이 많이 발생한다. 이에 대하여 Engle (1982)과 Bollerslev (1986)는 이분산 문제점을 다루는 방법으로 $\mathrm{ARCH}$ 와 GARCH 모형 을 제안했다. $\mathrm{GARCH}$ 모델은 분산에 대한 모형을 적용함으로서 모형의 추정 및 예측을 가능하게 한다. $\operatorname{AR}(k)-\operatorname{GARCH}(q, p)$ 모형은 다음과 같은 형태로 제안된다.

$$
\begin{aligned}
y_{t} & =\phi_{1} y_{t-1}+\phi_{2} y_{t-2}+\cdots+\phi_{k} y_{t-k}+\epsilon_{t}, \\
\epsilon_{t} & =e_{t} \sqrt{h_{t}}, \\
h_{t} & =\alpha_{0}+\sum_{j=1}^{p} \alpha_{j} \epsilon_{t-j}^{2}+\sum_{j=1}^{q} \beta_{j} h_{t-j} .
\end{aligned}
$$

이는, $e_{t} \sim \operatorname{iid} N\left(0, \sigma^{2}\right), \alpha_{0}>0, \alpha_{j} \geq 0, \beta_{j} \geq 0, \alpha_{j}+\beta_{j}<1$ 을 따른다. $p$ 는 $\mathrm{ARCH}$ 부분의 차수이고 $q$ 는 $\mathrm{GARCH}$ 부분의 차수이다. 만일 $q$ 가 0 이면 모형은 $\mathrm{ARCH}(p)$ 와 같아진다.

계절요소에 의한 영향을 예측하기 위하여 계절형 $\mathrm{AR}-\mathrm{GARCH}$ 모형은 다음과 같은 형태로 정의 된다.

$$
\begin{aligned}
& \phi_{p}(B) \Phi_{p_{1}}\left(B^{s_{1}}\right) \Pi_{p_{2}}\left(B^{s_{2}}\right) Y_{t}=\epsilon_{t}, \quad \epsilon_{t}=e_{t} \sqrt{h_{t}}, e_{t} \sim \text { iid } N\left(0, \sigma^{2}\right), \\
& h_{t}=\alpha_{0}+\sum_{j=1}^{p} \alpha_{j} \epsilon_{t-j}^{2}+\sum_{j=1}^{q} \beta_{j} h_{t-j}+\sum_{j=1}^{p_{1}} \alpha_{j s_{1}} \epsilon_{t-j s_{1}}^{2}+\sum_{j=1}^{q_{1}} \beta_{j s_{1}} h_{t-j s_{1}} \\
& \quad+\sum_{j=1}^{p_{2}} \alpha_{j s_{2}} \epsilon_{t-j s_{2}}^{2}+\sum_{j=1}^{q_{2}} \beta_{j s_{2}} h_{t-j s_{2}},
\end{aligned}
$$

여기서 $s_{1}, s_{2}$ 는 $t$ 시점에서 계절주기를 의미하며 $\mathrm{AIC}$ (Akaike information criterion)가 최소인 모형을 최적의 모형으로 고려한다.

\section{3. 자료 분석}

본 논문에서 이용한 자료는 2008년 1월 1일부터 2012년 3월 31일까지 한국 전력거래소에서 수집된 일 별 최대 전력수요 자료이다. 이 중 2008년 1월부터 2011년 12월 31일까지 4년간의 자료를 이용하여 모 형을 적합하고, 2012 년 1 월 1 일 부터 3 월 31 일까지의 3 개월간의 자료로 모형의 성능을 평가하였다.

우선 일별 최대 전력수요 원자료의 시계열 그림은 Figure 3.1과 같다. Figure 3.1을 보면 일년을 주기로 여름과 겨울에 다른 패턴을 보이는 것을 알 수 있다. 설 연휴와 추석 연휴에는 정규적인 계절패턴과 다 


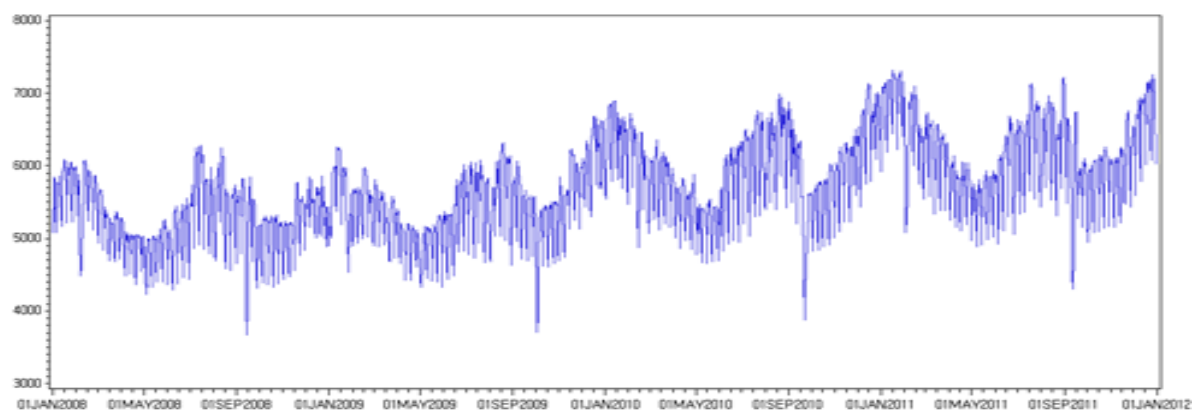

Figure 3.1. Time plot for daily max demand data

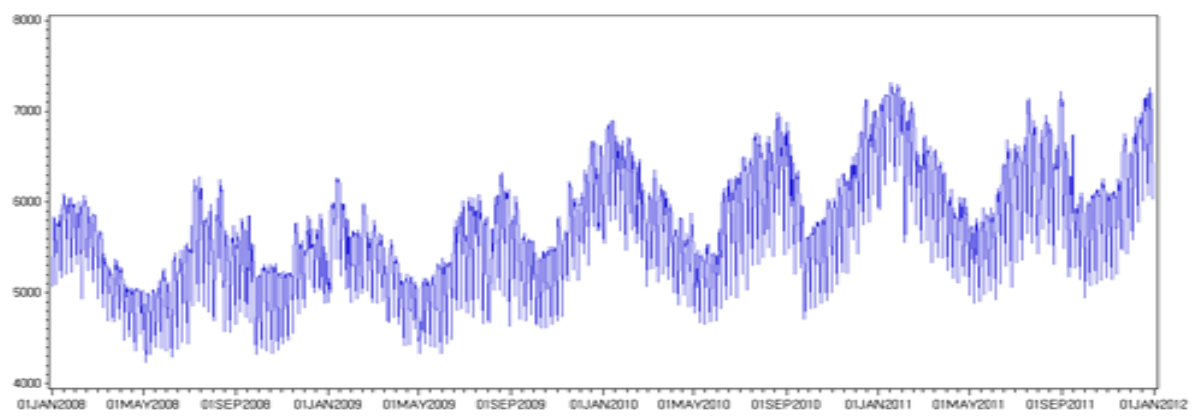

Figure 3.2. Time plot for adjusted holiday data

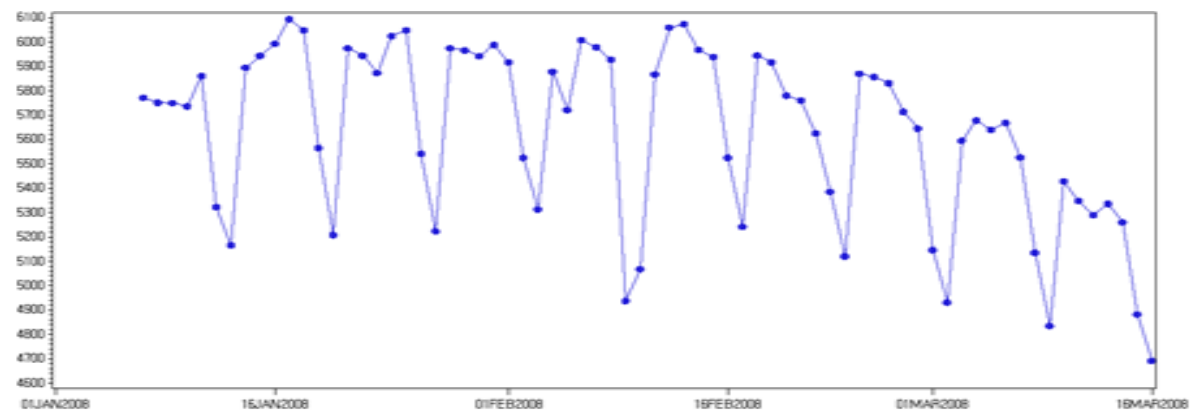

Figure 3.3. Time plot for daily max demand data in 10 weeks

른 수요를 보이는데, 4 년간 8 번의 설 연휴와 추석연휴에 대하여 그 전후 3 일에 대해 1 주일 전과 1 주일 후 같은 요일의 평균 수요값으로 대체하며, 이는 Figure 3.2 와 같다. Figure 3.2 의 그래프를 보면 추세 와 함께 계절성이 있으며 시간이 흐름에 따라 자료의 변동 폭이 커짐을 알 수 있다. Figure 3.3 의 10주 간의 일별 최대 전력수요 시계열 그림을 통해 일주일을 주기로 주중 패턴이 비슷하고 토요일과 일요일 은 다른 패턴을 보이는 것을 주기 7 을 고려할 것이며, 시간의 흐름에 따른 자료의 변동 폭이 증가하는 것으로 보아 로그변환을 실시한 후 정상성을 위해 7 차 차분을 한 $Z_{t}=\left(1-B^{7}\right) \ln Y_{t}$ 의 시계열 그림 은 Figure 3.4와 같다. $Z_{t}$ 를 이용하여 ARIMA, Reg-ARIMA, AR-GARCH 모형을 적합하였고, HoltWinters 모형은 원 자료를 이용하여 모수를 추정한다. 계절 주기의 길이를 각각 $s_{1}, s_{2}$ 로 표현하며, 주 별 주기와 연도별 주기를 7 과 364 로 설정한다. 


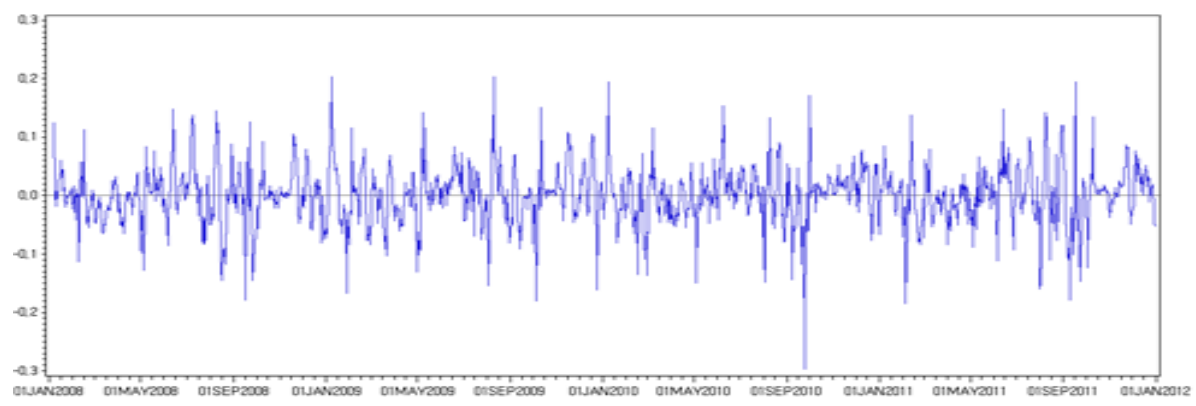

Figure 3.4. Time plot for $\log$ transformed and differenced with lag 7 data

Table 3.1. Estimates of Seasonal ARIMA

\begin{tabular}{cccc}
\hline 모수 & 추정값 & 표준오차 & $\mathrm{Lag}$ \\
\hline$\theta_{1}$ & 0.48250 & 0.08756 & 3 \\
$\Theta_{1}$ & 0.82379 & 0.01537 & 7 \\
$\phi_{1}$ & -0.26350 & 0.02627 & 1 \\
$\phi_{2}$ & -0.19798 & 0.02662 & 2 \\
$\phi_{3}$ & 0.30098 & 0.09304 & 3 \\
$\phi_{4}$ & 0.09048 & 0.03083 & 4 \\
\hline
\end{tabular}

\section{1. 분석 모형 설정}

모형은 계절주기를 주별로 7 일 하나만 사용한 단순 계절형 ARIMA, Holt-Winters, AR-GARCH 모형 과 계절주기로 주별과 연별을 고려하여 7 일과 364 일의 2 개의 계절주기를 이용한 이중 계절형 $\mathrm{ARIMA}$, Holt-Winters, Taylor의 수정된 Holt-Winters, AR-GARCH 모형을 사용한다. 또한 회귀변수를 고려 한 이중계절형 Reg-ARIMA 모형을 사용하며, Reg-ARIMA 모형에서 사용되는 사전조정을 위한 회 귀변수는 평균기온을 사용한다. 국내 연평균기온 $13.5^{\circ} \mathrm{C}$ 을 고려하여, 연평균기온보다 높은 평균기온을 $C_{1}$, 낮은 평균기온을 $C_{2}$ 으로 사용한다. 이는 식 (3.1)과 같다.

$$
C_{1}=\left\{\begin{array}{ll}
\text { 평균기온 }-13.5, & \text { if 평균기온 }>13.5, \\
0, & \text { if 평균기온 } \leq 13.5,
\end{array} \quad C_{2}= \begin{cases}13.5-\text { 평균기온, } & \text { if 평균기온 }<13.5, \\
0, & \text { if 평균기온 } \geq 13.5 .\end{cases}\right.
$$

평균기온은 서울, 강릉, 광주, 대전, 부산의 기상청에서 관측된 일평균기온을 통해, 전국 일 평균기 온으로 이용한다. 각 모형들의 성능 비교를 위하여 2 주간의 일별 예측과 1 달간의 예측값을 이용하여 $\mathrm{RMSE}$ 와 MAPE를 계산한다.

각 모형에서 최적의 모형을 선택한 결과 ARIMA 모형과 HW 모형의 모수 추정치는 Table 3.1 에서 Table 3.4와 같이 나타난다. 잔차들이 백색잡음인지 여부의 판정을 위한 포트맨토 검정 결과는 모든 시 차에서 유의하지 않아 모형을 적합하였다. 추정된 계절형 ARIMA 모형은 일반 MA항이 3 차만 유의한 $\operatorname{ARIMA}(4,1,3)(0,0,1) 7$ 이며, 이중계절형 $\mathrm{ARIMA}$ 모형은 일반 MA항 중 1,2 차가 유의하지 않고 일반 $\mathrm{AR}$ 항 중 3 차가 유의하지 않은 $\operatorname{ARIMA}(4,1,4)(1,0,2)_{7}(0,1,1)_{364}$ 으로 나타났다. Reg-ARIMA 모형은 $C_{1}$ 과 $C_{2}$ 를 고려한 $\operatorname{ARIMA}(3,0,2)(0,0,1)_{7}(0,0,1)_{364}$ 로 나타났다. Table 3.4에 나타난 Holt-Winters 모형의 모수는 $\mathrm{AIC}$ (Akaike's Information Criterion)값을 최소화하는 모형의 추정치를 선택하였다.

$\mathrm{AR}-\mathrm{GARCH}$ 모형 또한 $\mathrm{AIC}$ 가 최소인 모형을 선택하며, $\mathrm{GARCH}$ 항은 유의하지 않으므로 $\mathrm{ARCH}$ 모 형을 선택하였다. 추정된 계절형 $\mathrm{AR}-\mathrm{GARCH}$ 모형은 $\mathrm{AR}(3)(3)_{7}-\mathrm{ARCH}(1)(2)_{7}$ 이고, 이중계절형 $\mathrm{AR}-$ 
Table 3.2. Estimates of Double Seasonal ARIMA

\begin{tabular}{cccc}
\hline 모수 & 추정값 & 표준오차 & $\mathrm{Lag}$ \\
\hline$\theta_{3}$ & 0.37250 & 0.03132 & 3 \\
$\theta_{4}$ & 0.48902 & 0.04659 & 4 \\
$\Theta_{1}$ & 0.76825 & 0.02243 & 7 \\
$\psi_{1}$ & 0.51375 & 0.03239 & 364 \\
$\phi_{1}$ & -0.35058 & 0.02714 & 1 \\
$\phi_{2}$ & -0.30362 & 0.02924 & 2 \\
$\phi_{4}$ & 0.42698 & 0.04904 & 4 \\
\hline
\end{tabular}

Table 3.3. Estimates of Reg-ARIMA

\begin{tabular}{crcc}
\hline 모수 & 추정값 & 표준오차 & Lag \\
\hline$\theta_{1}$ & 1.37476 & 0.11815 & 1 \\
$\theta_{2}$ & -0.43045 & 0.11769 & 2 \\
$\Theta_{1}$ & 0.75453 & 0.01886 & 7 \\
$\psi_{1}$ & -0.13647 & 0.03100 & 364 \\
$\phi_{1}$ & 2.29019 & 0.10884 & 1 \\
$\phi_{2}$ & -1.79878 & 0.19229 & 2 \\
$\phi_{3}$ & 0.50101 & 0.08495 & 3 \\
$C_{1}$ & 0.00591 & 0.00082 & 0 \\
$C_{2}$ & 0.00415 & 0.00049 & 0 \\
\hline
\end{tabular}

Table 3.4. Estimates of Holt-Winters

\begin{tabular}{lccc}
\hline \multicolumn{1}{c}{ 모수 } & Holt-Winters & $\begin{array}{c}\text { 이중계절형 } \\
\text { Holt-Winters }\end{array}$ & $\begin{array}{c}\text { 수정 이중계절형 } \\
\text { Holt-Winters }\end{array}$ \\
\hline $\operatorname{Level}(\alpha)$ & 0.66114 & 0.53062 & 0.04280 \\
$\operatorname{Trend}(\beta)$ & 0.00154 & 0.00001 & 0.00037 \\
Seasonal1 $(\gamma)$ & 0.13877 & 0.26154 & 0.00163 \\
Seasonal2 $(\delta)$ & - & 0.42338 & 0.31918 \\
Autoregressive $(\phi)$ & - & - & 0.62439 \\
\hline
\end{tabular}

$\mathrm{GARCH}$ 모형은 $\mathrm{AR}(3)(2)_{7}(1)_{364}-\mathrm{ARCH}(1)(1)_{7}(1)_{364}$ 이다. Table 3.5과 Table 3.6은 모수 추정 결과 이다.

\section{2. 자료분석 결과}

모형의 성능비교를 위하여 RMSE(Root Mean Square Error)와 MAPE(Mean Absolute Percentage Error)를 사용하며, 이는 식 (3.2)와 같이 정의된다.

$$
\operatorname{RMSE}=\sqrt{\frac{1}{n} \sum_{t=1}^{n}\left(Z_{t}-F_{t}\right)^{2}}, \quad \mathrm{MAPE}=\frac{1}{n} \sum_{t=1}^{n}\left|\frac{Z_{t-1} F_{t}}{Z_{t}}\right| \times 100 \%,
$$

여기서 $n$ 은 자료 적합에 사용한 표본 수이고 $Z_{t}$ 는 $t$ 시점에 실제 값, $F_{t}$ 는 각 모형에 대한 예측 값이다. 추가적으로 Reg-ARIMA 모델을 사용한 예측값을 기준으로 다른 모형들과 비교를 한다.

Table 3.7 에서 RMSE값으로 2 주간의 일별 자료와 월간 자료의 미래 예측 평가를 한 결과 이중계절 형 수정 Holt-Winters 모형과 Reg-ARIMA 모형이 전반적으로 다른 모형에 비하여 우수함을 보였다. 
Table 3.5. Estimates of Seasonal AR-GARCH

\begin{tabular}{cccc}
\hline 모수 & 추정값 & 표준오차 & Lag \\
\hline$\phi_{1}$ & 0.66710 & 0.02621 & 1 \\
$\phi_{2}$ & 0.07260 & 0.03147 & 2 \\
$\phi_{3}$ & 0.08493 & 0.02676 & 3 \\
$\Phi_{1}$ & -0.67676 & 0.02704 & 7 \\
$\Phi_{2}$ & -0.40739 & 0.03058 & 14 \\
$\Phi_{3}$ & -0.15180 & 0.02642 & 21 \\
$\alpha_{0}$ & 0.00064 & 0.00002 & - \\
$\alpha_{1}$ & 0.19520 & 0.02890 & 1 \\
$\alpha_{1,7}$ & 0.13450 & 0.03130 & 7 \\
$\alpha_{2,7}$ & 0.05300 & 0.02070 & 14 \\
\hline
\end{tabular}

Table 3.6. Estimates of Double Seasonal AR-GARCH

\begin{tabular}{cccc}
\hline 모수 & 추정값 & 표준오차 & Lag \\
\hline$\phi_{1}$ & -0.28625 & 0.02604 & 1 \\
$\phi_{2}$ & -0.19129 & 0.02670 & 2 \\
$\phi_{3}$ & -0.15573 & 0.02608 & 3 \\
$\Phi_{1}$ & -0.66367 & 0.02491 & 7 \\
$\Phi_{2}$ & -0.34277 & 0.02485 & 14 \\
$\Pi_{1}$ & 0.16895 & 0.03008 & 364 \\
$\alpha_{0}$ & 0.00051 & 0.00003 & - \\
$\alpha_{1}$ & 0.18980 & 0.03200 & 1 \\
$\alpha_{1,7}$ & 0.25260 & 0.03730 & 7 \\
$\alpha_{1,364}$ & 0.10530 & 0.02200 & 364
\end{tabular}

Table 3.7. RMSE for the 2 weeks and 1 month post-sample period

\begin{tabular}{|c|c|c|c|c|c|c|c|c|}
\hline \multirow[b]{2}{*}{ RMSE } & \multicolumn{3}{|c|}{ 단순계절형 } & \multicolumn{5}{|c|}{ 이중계절형 } \\
\hline & ARIMA & HW & $\mathrm{ARCH}$ & ARIMA & HW & adj-HW & $\mathrm{ARCH}$ & $\begin{array}{c}\text { Reg- } \\
\text { ARIMA }\end{array}$ \\
\hline 1 day & 8.89 & 53.41 & 39.67 & 159.54 & 390.17 & 32.25 & 46.19 & 6.85 \\
\hline 2 day & 20.55 & 140.11 & 45.33 & 234.20 & 433.53 & 28.91 & 42.92 & 29.03 \\
\hline 3 day & 114.04 & 250.77 & 154.76 & 224.24 & 418.40 & 72.99 & 74.64 & 64.50 \\
\hline 4 day & 205.23 & 348.73 & 268.41 & 201.99 & 384.45 & 131.48 & 196.96 & 90.12 \\
\hline 5 day & 215.68 & 363.57 & 303.27 & 180.69 & 407.19 & 121.25 & 244.34 & 104.52 \\
\hline 6 day & 231.21 & 387.38 & 322.19 & 169.61 & 439.21 & 113.91 & 266.59 & 147.98 \\
\hline 7 day & 233.27 & 382.70 & 322.82 & 161.91 & 448.72 & 111.10 & 264.76 & 154.21 \\
\hline 8 day & 229.64 & 377.28 & 315.78 & 158.86 & 470.44 & 120.71 & 256.70 & 156.70 \\
\hline 9 day & 225.46 & 384.80 & 309.09 & 169.65 & 505.70 & 126.79 & 249.02 & 166.56 \\
\hline 10 day & 216.82 & 383.54 & 300.49 & 194.75 & 547.37 & 132.65 & 240.90 & 162.07 \\
\hline 11 day & 219.29 & 394.43 & 309.30 & 190.81 & 567.25 & 130.95 & 246.73 & 157.94 \\
\hline 12 day & 215.19 & 393.43 & 316.95 & 187.70 & 600.93 & 137.26 & 253.10 & 156.21 \\
\hline 13 day & 211.94 & 394.72 & 317.28 & 190.70 & 631.29 & 138.88 & 256.99 & 166.66 \\
\hline 14 day & 206.27 & 386.55 & 312.88 & 200.23 & 642.58 & 157.12 & 255.08 & 165.73 \\
\hline 1month & 234.22 & 337.82 & 293.93 & 296.92 & 601.38 & 241.96 & 268.31 & 215.18 \\
\hline 2 month & 302.07 & 318.75 & 354.52 & 275.45 & 493.63 & 269.97 & 443.00 & 207.19 \\
\hline 3 month & 631.41 & 351.14 & 309.07 & 261.12 & 502.65 & 254.27 & 454.83 & 217.00 \\
\hline
\end{tabular}


Table 3.8. MAPE for the 2 weeks and 1 month post-sample period

\begin{tabular}{|c|c|c|c|c|c|c|c|c|}
\hline \multirow[b]{2}{*}{ RMSE } & \multicolumn{3}{|c|}{ 단순계절형 } & \multicolumn{5}{|c|}{ 이중계절형 } \\
\hline & ARIMA & HW & $\mathrm{ARCH}$ & ARIMA & HW & adj-HW & $\mathrm{ARCH}$ & $\begin{array}{c}\text { Reg- } \\
\text { ARIMA }\end{array}$ \\
\hline 1 day & $0.15 \%$ & $3.22 \%$ & $0.68 \%$ & $2.75 \%$ & $6.71 \%$ & $0.56 \%$ & $0.80 \%$ & $0.12 \%$ \\
\hline 2 day & $0.28 \%$ & $3.87 \%$ & $0.71 \%$ & $3.48 \%$ & $6.78 \%$ & $0.46 \%$ & $0.68 \%$ & $0.35 \%$ \\
\hline 3 day & $1.09 \%$ & $5.05 \%$ & $1.68 \%$ & $3.26 \%$ & $6.32 \%$ & $0.86 \%$ & $0.99 \%$ & $0.72 \%$ \\
\hline 4 day & $2.06 \%$ & $6.18 \%$ & $2.86 \%$ & $2.83 \%$ & $5.62 \%$ & $1.44 \%$ & $2.02 \%$ & $1.02 \%$ \\
\hline 5 day & $2.35 \%$ & $6.62 \%$ & $3.43 \%$ & $2.28 \%$ & $5.85 \%$ & $1.33 \%$ & $2.66 \%$ & $1.23 \%$ \\
\hline 6 day & $2.64 \%$ & $7.00 \%$ & $3.79 \%$ & $2.12 \%$ & $6.19 \%$ & $1.26 \%$ & $3.04 \%$ & $1.66 \%$ \\
\hline 7 day & $2.80 \%$ & $7.07 \%$ & $3.97 \%$ & $2.05 \%$ & $6.42 \%$ & $1.29 \%$ & $3.17 \%$ & $1.84 \%$ \\
\hline 8 day & $2.87 \%$ & $7.16 \%$ & $4.01 \%$ & $2.07 \%$ & $6.84 \%$ & $1.48 \%$ & $3.16 \%$ & $1.96 \%$ \\
\hline 9 day & $2.84 \%$ & $7.24 \%$ & $3.95 \%$ & $2.21 \%$ & $7.21 \%$ & $1.58 \%$ & $3.08 \%$ & $2.10 \%$ \\
\hline 10 day & $2.71 \%$ & $7.24 \%$ & $3.84 \%$ & $2.48 \%$ & $7.66 \%$ & $1.67 \%$ & $2.98 \%$ & $2.05 \%$ \\
\hline 11 day & $2.77 \%$ & $7.39 \%$ & $3.98 \%$ & $2.43 \%$ & $7.89 \%$ & $1.66 \%$ & $3.09 \%$ & $2.00 \%$ \\
\hline 12 day & $2.73 \%$ & $7.44 \%$ & $4.10 \%$ & $2.40 \%$ & $8.26 \%$ & $1.74 \%$ & $3.19 \%$ & $1.99 \%$ \\
\hline 13 day & $2.70 \%$ & $7.48 \%$ & $4.13 \%$ & $2.46 \%$ & $8.61 \%$ & $1.78 \%$ & $3.27 \%$ & $2.12 \%$ \\
\hline 14 day & $2.63 \%$ & $7.38 \%$ & $4.11 \%$ & $2.62 \%$ & $8.86 \%$ & $1.99 \%$ & $3.29 \%$ & $2.14 \%$ \\
\hline 1 month & $2.49 \%$ & $6.36 \%$ & $3.96 \%$ & $3.56 \%$ & $7.84 \%$ & $2.72 \%$ & $3.51 \%$ & $2.28 \%$ \\
\hline 2 month & $3.25 \%$ & $5.93 \%$ & $4.66 \%$ & $3.30 \%$ & $6.09 \%$ & $3.16 \%$ & $5.79 \%$ & $2.29 \%$ \\
\hline 3 month & $7.36 \%$ & $5.03 \%$ & $3.91 \%$ & $3.14 \%$ & $6.49 \%$ & $2.94 \%$ & $6.27 \%$ & $2.50 \%$ \\
\hline
\end{tabular}

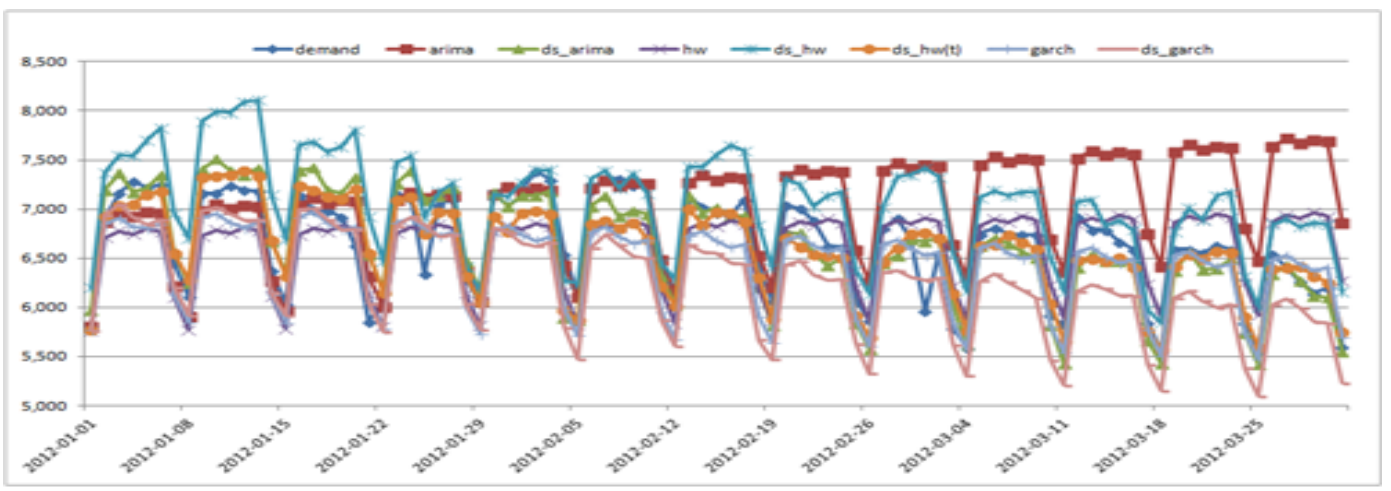

Figure 3.5. Time plot of each model

수정 Holt-Winters 모형은 단기 2주간의 예측에서 예측이 우수하나 장기 예측으로 갈수록 그 예측력 이 떨어짐을 알 수 있다. Reg-ARIMA는 장기 예측에서도 다른 모형보다 우수한 예측력을 보이며 3 달 후의 미래예측에서도 $2.5 \%$ 의 오차율로 우수한 성능을 보인다. 이는 최대전력수요량 예측에서 기온에 의한 영향을 고려한 모형이 최대전력량만을 이용한 분석보다 더 정확한 예측이 가능함을 알 수 있다. 2 주간의 예측에서는 이중계절형 수정 Holt-Winters 모형이 가장 나은 예측을 보여주는데, 기존 HoltWinters 방법보다 자기회귀항을 고려한 수정 Holt-Winters 모형이 단기간 전력 수요예측에서 나은 결 과를 보여줌을 의미한다. Table 3.8은 MAPE값으로 각각의 모형을 비교한 것으로, RMSE값과 마찬가 지로 수정 Holt-Winters 모형과 Reg-ARIMA가 작은 MAPE값으로 전반적으로 우수한 성능을 보인다.

Figure 3.5 는 3 달간의 예측 기간에서 실제 최대 전력수요 값과 각 모형의 예측값을 나타낸 그래프이다. 
예측 기간이 길어질수록 단순계절형 ARIMA 모형이 실제값과 큰 차이를 보이며 점점 증가하는 추세 를 보인다. 이는 일주일 주기만을 고려한 단순계절형 모형이 증가하는 추세를 그대로 반영했기 때문으 로, 실제로 1 월부터 다시 감소하는 계절 추세를 모형에 반영하지 못함을 의미한다. 이중계절형 HoltWinters 모형의 경우 실제값과 큰 차이를 가지는 반면, 수정 Holt-Winters 모형은 거의 근사한 예측값 을 가진다. 이는 수정 Holt-Winters 모형의 자기회귀항이 실제 값과 근사한 예측을 할 수 있게 해주기 때문이다. $\mathrm{AR}-\mathrm{ARCH}$ 모형이 다른 모형에 비해 상대적으로 좋지 않은 성능을 보이는 이유는 자료가 일 일간격으로 얻어진 것이기 때문에 시간당 자료에 비해 변동성이 작아서라고 볼 수 있다.

\section{4. 결론}

본 논문에서는 계절추세가 있는 시계열 자료를 예측하는 다양한 모형을 소개하고 국내 일별 최대 전력 수요량을 예측했다. 기존의 기법들과 수정된 Holt-Winters 모형과 평균기온을 고려한 Reg-ARIMA 모 형을 통한 최대전력수요 예측을 시도하였으며, 시계열 예측 모형을 적합할 때 단순 계절형 모형의 사용 과 이중 계절형 모형의 사용에 따른 예측 결과를 비교하여 예측 기간에 따라 어떤 모형이 우수한지 비 교하였다. 최대 전력 수요자료를 이용하여 총 8 가지의 계절형 모형에 적합해 본 결과, 2 주간의 단기 예 측에서 자기회귀항을 고려한 수정된 Holt-Winters 모형이 우수함을 보였고, 평균기온을 고려한 RegARIMA 모형은 전반적으로 오차율 $2.5 \%$ 이내의 우수한 예측결과를 보였다. 전력 수요 자료의 경우 계 절과 요일별 수요 차가 뚜렷하기 때문에 계절형 모형을 적용하여 예측하는 것은 중요하고 계속된 연구가 필요할 것이다. 좀 더 정확한 예측을 위해 일별 자료가 아닌 더 짧은 주기의 자료를 이용하여 시간별 주 기까지 고려한 뒤 분석한다면 더 나은 결과를 얻을 수 있을 것이라 생각된다. 특히 GARCH 모형의 경 우 본 연구에서는 성능이 그리 좋지 않았는데 그 이유로 일별 자료는 시간별 자료에 비하여 상대적으로 변동성이 작기 때문으로 볼 수 있다. 그러므로 시간 주기를 고려하여 모형을 적합한다면 시간에 따른 변 동성을 잘 설명할 수 있는 $\mathrm{GARCH}$ 모형에서 우수한 성능을 예상한다. 차후적으로 자기회귀항을 변형 한 모형을 고려하여야 하며, 기상현상을 보정하기 위한 모형에 대한 개발을 시도하여야 할 것이다. 또한 특정 시간대의 변동성을 잘 설명하는 예측을 위해 앞으로도 계속된 연구가 필요할 것이다.

\section{References}

Amjady, N. (2001). Short-Term Hourly Load Forecasting Using Time-Series Modeling with Peak Load Estimation Capability, IEEE Transactions on Power Systems, 16, 498-505.

Bollerslev, T. (1986). Generalized autoregressive conditional heteroskedasticity, Journal of Econometrics, 31, 307-327.

Box, G.E.P. and Jenkins, G.M.(1994)., Time Series Analysis, Forecasting and Control, Prentice Hall.

Engle, R. F. (1982). Autoregressive conditional heteroscedasticity with estimates of the variance of United Kingdom inflation, Econometrica: Journal of the Econometric Society, 50, 987-1007.

McSharry, P. E., Bouwman, S. and Bloemhof, G. (2005). Probabilistic forecasts of the magnitude and timing of peak electricity demand , IEEE Transactions on Power Systems, 20, 1166-1172.

Ramanathan, R., Engle, R., Granger, C. W. J., Vahid-Araghi, F. and Brace, C. (1997). Short-run forecasts of electricity loads and peaks, International Journal of Forecasting, 13, 161-174.

Sohn, S. Y. and Lim, M. (2005). Hierarchical forecasting based on AR-GARCH model in a coherent structure European, Journal of Operational Research, 176, 1033-1040.

Taylor, J. W. (2003). Short-term electricity demand forecasting using double seasonal exponential smoothing, Journal of the Operational Research Society, 54, 799-805.

Taylor, J. W. (2010). Triple seasonal methods for short-term electricity demand foreca-sting, European Journal of Operational Research, 204, 139-152. 
Taylor, J. W. and Buizza, R. (2003). Using weather ensemble predictions in electricity demand forecasting, International Journal of Forecasting, 19, 57-70.

Weron, R. (2006). Modeling and Forecasting Electricity Loads and Prices: A Statistical Approach, Wiley, Chichester.

Winters, P. R. (1960). Forecasting sales by exponentially weighted moving averages, Management Science, 6, 324-342. 


\section{시계열 모형을 이용한 일별 최대 전력 수요 예측 연구

\author{
이정순 ${ }^{a} \cdot$ 손흥구 $^{a} \cdot$ 김삼용 ${ }^{a, 1}$ \\ ${ }^{a}$ 중앙대학교 응용통계학과
}

(2013년 2월 26일 접수, 2013년 4월 5일 수정, 2013년 4월 5일 채택)

\section{요 약}

최근 일별 최대 전력수요 예측은 전력설비 계획 및 운용에 매우 중요한 사안으로 주목받고 있다. 본 연구는 일별 최대 전력수요 예측을 위하여 대표적 시계열 모형을 소개하고, 예측의 성능 비교를 위하여 RMSE(Root mean squared error)와 MAPE(Mean absolute percentage error)를 사용한다. 연구결과로 보완된 Holt-Winters 모 형과 Reg-ARIMA 모형이 다른 모형에 비하여 우수한 예측 성능을 보였다.

주요용어: AR-GARCH 모형, Holt-Winters 모형, Reg-ARIMA 모형, 전력수요, 최대전력치.

이 논문은 2011년도 중앙대학교 연구장학기금 지원에 의한 것임.

${ }^{1}$ 교신저자: (156-756) 서울 동작구 흑석동 221, 중앙대학교 응용통계학과, 교수. E-mail: sahm@cau.ac.kr 